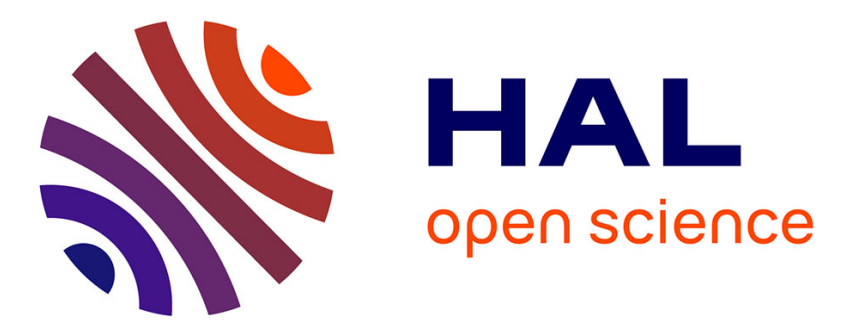

\title{
Letter coding affects movement production in word writing: an English-Italian cross-linguistic study
}

Sonia Kandel, Ronald Peereman, Anna Ghimenton, Cyril Perret

\section{To cite this version:}

Sonia Kandel, Ronald Peereman, Anna Ghimenton, Cyril Perret. Letter coding affects movement production in word writing: an English-Italian cross-linguistic study. Reading and Writing, 2019, 32 (1), pp.95-114. 10.1007/s11145-017-9756-y . hal-01983485

\section{HAL Id: hal-01983485 https://hal.science/hal-01983485}

Submitted on 22 Jan 2019

HAL is a multi-disciplinary open access archive for the deposit and dissemination of scientific research documents, whether they are published or not. The documents may come from teaching and research institutions in France or abroad, or from public or private research centers.
L'archive ouverte pluridisciplinaire HAL, est destinée au dépôt et à la diffusion de documents scientifiques de niveau recherche, publiés ou non, émanant des établissements d'enseignement et de recherche français ou étrangers, des laboratoires publics ou privés. 


\title{
Letter coding affects movement production in word writing: an English-Italian cross-linguistic study
}

\author{
Sonia Kandel ${ }^{1} \cdot$ Ronald Peereman $^{2} \cdot$ Anna Ghimenton $^{3} \cdot$ Cyril Perret $^{4}$
}

(C) Springer Science+Business Media B.V. 2017

\begin{abstract}
The present research is a cross-linguistic study indicating that the timing of motor production not only depends on the shape of a letter and the activation of its motor program but also on the way the orthographic representations encode the letters for spelling retrieval. English and Italian-speaking participants wrote cognate words (e.g., DISSIPATE-DISSIPARE) on a digitizer. The words contained a doublet. They were matched to words that shared the initial letters and differed on the presence of a double letter (e.g., DISSIPATE/DISGRACE in English and DISSIPARE/DISGRAZIA in Italian). The results revealed that the presence of a doublet in English and Italian words accelerated motor production with respect to control words. Word production seems to be modulated by the way orthographic representations encode letters, but the way doublet coding affects writing differs among languages. The impact of letter doubling seems to be stronger in Italian than English. The data provide further evidence indicating that the processes involved in spelling retrieval spread into the processes that regulate movement execution.
\end{abstract}

Keywords Double letters · Handwriting · English · Italian

Sonia Kandel

sonia.kandel@gipsa-lab.fr

1 Univ. Grenoble Alpes, GIPSA-lab (CNRS UMR 5216), 1180, avenue Centrale - BP 25, 38031 Grenoble Cedex 09, France

2 LPNC (CNRS UMR 5105), Univ. Grenoble Alpes, Grenoble, France

3 Univ. Lyon 2, DDL (CNRS UMR 5596), Lyon, France

4 Univ. Poitiers, CeRCA (UMR 7295 - CNRS), Poitiers - Univ. Tours, Tours, France 


\section{Introduction}

Knowing how to write is an essential skill in everyday life. To write a word, we retrieve its spelling and then write the letters by producing hand movements with a pen/pencil or keyboard. Experimental research on spelling processes generally measures reaction time to examine the processes that are active before we start to write (Afonso \& Alvarez, 2011; Bonin, Peereman, \& Fayol, 2001; Qu, Damian, Zhang, \& Zhu, 2011; Zhang \& Damian, 2010). The studies on the motor aspects of written production investigate movement kinematics. In this perspective, when we write a letter, we retrieve its shape and motor program (Teulings, Thomassen, \& Van Galen, 1983; Van Galen, Smyth, Meulenbroek, \& Hylkema, 1989). This information will determine the movements to produce it. So according to this view, writing words involves the activation of its letter components in a linear fashion (Van Galen, 1991). This means that we should always write a letter in the same way, despite its linguistic counterpart. It is unlikely however that to write a word we program mechanically one letter after another without applying any kind of mnemonic strategy to facilitate the retrieval of the correct spelling. We posit that spelling processes interact with motor processes to optimize word production. The present research is a cross-linguistic English-Italian study indicating that the timing of motor production not only depends on the shape of the letters we have to write but also on the way the orthographic representations encode these letters for spelling retrieval.

Research on a variety of cognitive functions have shown that when we have to retrieve several elements in a sequence, we tend to group small units into bigger chunks. Several studies (e.g., Jenkins \& Russel, 1952) suggested a long time ago that this processing strategy is particularly efficient for memorizing and retrieving strings with several elements. Chunking elements into bigger units is more efficient because we attribute some kind of meaning that becomes a mnemonic cue. In writing, phonology can be the cue that determines the way the writing system assembles letters into chunks. In French for example, Kandel and Spinelli (2010) conducted a word writing study indicating that when letter $\mathrm{A}$ is pronounced /a/ like in the word CLAVIER (keyboard) it is processed as a single unit. But when A is associated to I, like in PRAIRIE (meadow), it is pronounced / $\varepsilon /$ because it belongs to the complex grapheme AI. The writing system will process AI as a chunk. The timing of motor production for writing letter A in CLAVIER is shorter than when producing it in PRAIRIE. So the timing of letter production not only depends on its shape - the shape of letter A-but also on the way the orthographic representations encode its phonological counterpart.

The present study addresses the question of letter doubling. Are double letters chunked together into a bigger unit? Most of us have written at least once a double letter in a word that is not the letter that has to be doubled (e.g., MISSING $\rightarrow$ *misinng; in upper case we present the correct spelling and after the arrow, in lower case, we present the production; the * indicates that the letter sequence is not a word). What happens is that we know that a letter in the word has to be doubled but we do not remember which one it is. How do we know that we have to double a letter when we write a word? Is there a special coding for double letters in orthographic representations? Neuropsychological 
data on spelling errors of Italian and English-speaking dysgraphic patients suggest that this happens because orthographic representations code letter identity and quantity independently (McCloskey, Baddecker, Goodman-Schulman, \& Aliminosa, 1994; Tainturier \& Caramazza, 1996). What we do not know is the kind of information that is being processed while we write. Is processing words with double letters more or less time consuming than words without double letters? Are double letters chunked together? In the present research the participants wrote words in English and Italian on a digitizer. The digitizer provided on-line kinematic measures on the handwriting movement and allowed us to observe the effect of letter doubling before the participants started to write the word and while they wrote it. Previous experiments suggest that double letters are represented as independent chunks. They are activated simultaneously with the orthographic representation of the word. This activation spreads and affects the timing of word writing (Afonso, Suárez-Coalla \& Cuetos, 2015a, Afonso, Álvarez \& Kandel, 2015b; Álvarez, Cottrell, \& Afonso, 2009; Buchwald \& Falconer, 2014; Delattre, Bonin, \& Barry, 2006; Kandel, Spinelli, Tremblay, Guerassimovitch, \& Álvarez, 2012; Lambert \& Quemart, 2015; Lambert, Alamargot, Larocque, \& Caporossi, 2011; Roux, McKeeff, Grosjacques, Afonso, \& Kandel, 2013; Sausset, Lambert, Olive, \& Larocque, 2012). It modulates the peripheral aspects of motor production throughout the word.

The first studies on written language production assumed that the orthographic representations that we activate to write a word code information on letter identity and order (Caramazza, Miceli, Villa, \& Romani, 1987; Van Galen, 1991; Wing \& Baddeley, 1980). The word "missing" for example would be represented as $\mathrm{M}_{1} \mathrm{I}_{2} \mathrm{~S}_{3} \mathrm{~S}_{4} \mathrm{I}_{5} \mathrm{~N}_{6} \mathrm{G}_{7}$. Neuropsychological studies soon argued against this linear conception of orthographic representations on the basis of the spelling performance of dysgraphic patients. Caramazza and Miceli (1990) suggested that orthographic representations are multi-dimensional structures that code information on various levels of linguistic processing. The spelling errors of an English-speaking dysgraphic patient point to the idea that letter identity and quantity are coded at different representational levels (McCloskey et al., 1994). Patient HE exhibited twice as many spelling errors for words with embedded double letters than for equivalent words without double letters. Furthermore, $83 \%$ of the errors in the words containing double letters concerned the doublet (e.g., CROSS $\rightarrow{ }^{*}$ croos). The analyses conducted by Tainturier and Caramazza (1996) further indicated that double letters do not follow the same error patterns as letters that appear twice within a word but not in adjacent positions (e.g. CACTUS) or as clusters that represent a phoneme (e.g., ROCKET where $\mathrm{CK}=\overline{/ \mathrm{k}} / \overline{\text { ) }}$. This suggests that brain damage may selectively affect grapheme identity or quantity (see Miceli, Benvegnú, Capasso, \& Caramazza, 1995; Venneri, Cubelli, \& Caffara, 1994 in Italian; and in English Ellis, Young, \& Flude, 1987).

Data from non-brain impaired individuals supporting this view is rather scarce. Some studies on spelling acquisition provided evidence for a specific processing of double letters. English-speaking first graders considered pseudo-words that had an embedded "legal" and frequent doublet (e.g., LL) as more word-like than pseudowords that had an "illegal" doublet (e.g., HH, Cassar \& Treiman, 1997). Other studies with French-speaking first to fourth graders revealed that they preferred 
pseudo-words that had a doublet in medial position than in other positions that are illegal in French (Pacton, Perruchet, Fayol, \& Cleeremans, 2001; Pacton, Sobaco, Fayol, \& Treiman, 2013; Pacton, Borchardt, Treiman, Lété, \& Fayol, 2014). Orthographic learning was better when the pseudo-words included a frequent doublet (e.g., NN) than when they included an infrequent doublet (DD). Furthermore, there were more transpositions of the doubling feature to another consonant for infrequent doublets (*TIDDUNAR retrieveded as *TIDUNNAR). This kind of letter processing seems to be present as soon as the children become familiar with written language. As in the neuropsychological studies, the analyses in these experiments were conducted on off-line measures. Although they are extremely informative in many aspects, they do not give insight on how doublet coding in orthographic representations affects the writing process on-line.

Some typing studies did provide on-line data (Sternberg, Knoll, \& Turock, 1990). The duration of inter-key intervals in consonant sequences containing double letters (e.g., SCCRZ) were shorter than in equivalent sequences not containing double letters (e.g., SFCRZ). The authors considered that "the production of strings that include a doublet indicates that the two strokes of the doublet are contained in the same action unit" (Sternberg, Knoll, Monsell, \& Wright, 1983, p. 41). The authors were not concerned by orthographic representations and did not argue in favor of a specific processing level for double letter coding. Later, some studies revealed that letter chunking strategies in typewriting can be determined by the linguistic structure of word representations (Weingarten, 2005; Weingarten, Nottbusch, \& Will, 2004).

Studies on handwriting production suggest that movement production is constrained by the spatial or geometric parameters of a letter, of course, but also by the type of letter chunks we activate when we retrieve the spelling of a word. French participants wrote words in upper-case letters on a digitizer (Kandel, Alvarez, \& Vallée, 2006). As in the typing studies, the authors measured the duration of the intervals between letters. They compared the intervals in words sharing the initial letters but with different syllable boundary positions (e.g., PRI.SON and PRIS.ME, the dot indicates the syllable boundary). The results revealed that the duration of the interval between the letters at the syllable boundary (IS in PRI.SON) was longer than the same interval in a within syllable position (IS in PRIS.ME). The IS intervals were longer when they were located at the syllable boundary because the motor system anticipated the production of the following syllable. For within-syllable IS intervals the movement to produce the syllable had already been programmed before starting to write, so there was no need for further processing at this level. Therefore, letters are not produced in a linear fashion, one after the other, but are assembled into bigger chunks - i.e., syllables - that regulate motor programming during handwriting production. These duration differences can be accounted for by the anticipatory character of movement production proposed by Van Galen's (1991) handwriting model. The inter-letter interval durations at syllable boundaries were longer than at within-syllable positions because the motor system anticipated on-line the information to produce the second syllable of the word at the syllable boundary (between I and S in PRI.SON). At the within-syllable interval (IS in PRIS.ME) the information to produce the first syllable was probably 
programmed before starting to write. The parallel processing for the production of this interval is more limited and therefore less time consuming than at the syllable boundary. The problem with Van Galen's model is that it postulates that the spelling processing module codes words as linear strings of letter identities. In this view, intervals at syllable boundaries and within-syllable positions should be equivalent. This is at odds with Kandel et al.'s (2006) results.

To deal with this theoretical obstacle, Kandel, Peereman, Grosjacques and Fayol (2011) revisited Van Galen's (1991) model. They presented a model of handwriting production in which words are not conceived as linear letter strings but as multidimensional orthographic representations (cf., Caramazza \& Miceli, 1990; Miceli et al., 1995). In this perspective, the word representations adults and children activate while they write, code letter identity and order at the lower level dimensions but also other kinds of linguistic information such as syllable structure (e.g., $\mathrm{PRAI}_{1} \mathrm{RIE}_{2}$ ) in higher order dimensions. This writing strategy optimizes the retrieval of spelling because it conveys meaningful information in a phonologically coherent fashion. This facilitates the programming of motor outputs (Kandel \& Valdois, 2006a, b). This psycholinguistic model also includes a processing level that considers information on letter co-occurrences. Frequent bigrams lead to shorter writing times than infrequent ones (Kandel et al., 2011). However, there are frequent bigrams, as complex graphemes (e.g., $\mathrm{AI}=/ \varepsilon /$ in $\mathrm{P}_{1} \mathrm{R}_{2} \mathrm{AI}_{3} \mathrm{R}_{4} \mathrm{IE}_{5}$ ) that have a special status because they are directly linked to grapho-phonological conversion rules (Kandel \& Spinelli, 2010).

Other studies on handwriting production revealed that bigrams such as double letters (e.g., MISSING) also have a special status and are coded at a different level of orthographic representation (e.g., $\mathrm{M}_{1} \mathrm{I}_{2} \mathrm{SS}_{3} \mathrm{I}_{4} \mathrm{~N}_{5} \mathrm{G}_{6}$ ). English-speaking participants wrote words that contained double letters (e.g., DISSIPATE, Doublet words hereafter, Kandel et al., 2013). These productions were compared to the productions of words that shared the initial letters but did not have identical adjacent letters (e.g., DISGRACE, Control words hereafter). Latency (i.e., time before movement initiation), letter duration (e.g., D, I, S and S or G, respectively) and interval duration (e.g., DI, IS, SS or SG, respectively) were longer in Control than in words containing doublets. This suggests that the effects related to central processing (orthographic retrieval and motor programming) then spread into motor-response execution. The information on letter doubling was therefore active while writing the initial letters and before the doublet appeared in the word. This early processing modulated the timing of movement production. At the more local level-i.e., when the doublet occurred-the fourth letter (e.g., the second S in DISSIPATE and G in DISGRACE) was always longer in control than doublet words. The second $S$ in DISSIPATE was anticipated and programmed beforehand when the doublet was processed. At the moment the $S$ was being produced, the system processed the local parameters required for letter production. In contrast, the programming of the $G$ of DISGRACE did not benefit from a specific anticipation, so its production was more time consuming than the $\mathrm{S}$ of DISSIPATE. This supports the idea that the orthographic representations the system activates when we have to write a word have a specific coding for double letters. Another experiment conducted in French corroborates these findings although the English and French data are contradictory 
on the direction of the effect of letter doubling (Kandel, Peereman, \& Ghimenton, 2014). Producing LIS in a doublet word like LISSER (to smooth) was more time consuming than in controls (e.g., LISTER, to list).

The differential impact of letter doubling in French and English suggests that the predictability of doublet occurrence might diverge between languages. Among graphotactic restrictions for doubling, Carney (1994) noted that English doublets do not generally occur after a vowel composed of more than one letter. A similar observation holds for French in mono-morphemic words (an exception is OU which represents vowel $/ \mathrm{u} / \mathrm{)}$ ). Other fine-grained analyses at the orthographic level were reported by Berg (2016): more than $80 \%$ of English words ending with -ow or -ock included a single vowel followed by a double consonant (e.g., SORROW, HADDOCK). However, although graphotactic cues for letter doubling might differ between English and French, such cues appear to be restricted to very few word endings. Apart from etymological and morphological cues, phonological properties could be relevant to indicate letter doubling. In particular, according to Carney (1994) long vowels (or diphthongs) are generally not followed by double consonant letters. The word corpus analyses reported by Berg (2016) on bi-syllabic English words (stressed on the first syllable) indicate that short vowels were followed by double consonants in $69 \%$ of the cases. Conversely, double consonants were exceptional $(<1 \%)$ when preceded by a long vowel. Note that the predictive relation between vowel quality and doubling might be supplemented by a retrospective relation since, in trochaic structures, single consonants are preceded by a long vowel in $58 \%$ of the cases (Berg, 2016).

A recent study by Treiman and Kessler (2015) is also of interest here even if not restricted to letter doublets. The authors instructed a group of participants to spell mono-syllabic pseudo-words ending with a vowel followed either by a consonant that could be spelled with a single letter (simple spelling; e.g., F or FF for /f/ ) or a complex grapheme (extended spelling; e.g., $\mathrm{K}$ or $\mathrm{CK}$ for $/ \mathrm{k} /$ ). When the vowel was short (lax vowels) and spelled with a single letter, the extended spelling of the final consonant was observed in $81 \%$ of the spelling productions. The proportion decreased to $61 \%$ when the vowel was long (tense vowels). It is thus likely that the English-speaking participants in the Kandel et al. (2013) study were influenced by vowel quality (short/long). This kind of cues were not available for the French participants (Kandel et al., 2014). So, while French does not inform on the presence of doublets in mono-morphemic words, English doublets are partially cued by the quality of the preceding vowel and the orthographic length of the vowel.

Italian constitutes an interesting case to investigate the contribution of phonological factors on the spelling processes of doublet words. Indeed, letter doublets in Italian have a phonological counterpart corresponding to gemination. Gemination refers to a lengthening in the realization of the consonant with respect to a single consonant. In Italian, word-internal gemination is lexically contrastive (Krämer, 2009). For example, pronunciation of the nasal $/ \mathrm{m} /$ is shorter in CAMINO (chimney) than in CAMMINO (path). Durational measurements indicate that closure duration of geminate stop consonants (Esposito \& Di Benedetto, 1999) and the duration of geminate nasals (Mattei \& Di Benedetto, 2000) are about twice the duration of singletons, although differences between geminates and non-geminates 
are modulated by consonant types and stress position (Payne, 2005). More recently, Tagliapietra and McQueen (2010) showed that Italian listeners exploit consonant duration for lexical identification. Visual recognition of words with doublets (e.g., ALLARME, alarms) was facilitated when the same words in auditory priming sentences were pronounced with a long consonant with respect to a short consonant (the /l/ of ALANO, dog great Dane). Furthermore, consonant duration also appeared to assist continuous speech segmentation.

The purpose of the present study was to provide further evidence indicating that the orthographic and phonological representations activated during word production interact with the motor processes during movement production. If phonological information contributes to spelling production, the duration of the geminate consonants should constitute a relevant cue to facilitate movement production of Italian words. Additionally, if central processes interact continuously with the motor processes during production, the presence of doublets should start to affect the kinematics of handwriting production before the letter doubling is actually produced. An additional objective of the present experiment was to contrast the influence of letter doubling in Italian and English. To that end, we conducted an experiment in Italian to compare the data with the English results described in the Kandel et al. (2013) study.

\section{Methods}

\section{Participants}

The 20 English-speaking participants were the same as in Kandel et al. (2013). They were attending Harvard University for summer courses. The experimental design was approved by the Harvard IRB committee. The new data concern 20 Italianspeaking participants. They were Italian Erasmus Exchange Program students at the University of Grenoble. The study is in agreement with the guidelines of the ethical committee for Cognitive Science experiments in Grenoble. All the participants were right-handed, had normal or corrected-to-normal vision, and no motor or hearing disorders. They were unaware of the purpose of the experiment. They were native English and Italian speakers, respectively.

\section{Materials}

Most of the Italian stimuli were cognates of the English words used in Kandel et al.'s (2013) experiment (Appendix 1). In each language, the words had a doublet at positions 3 and 4 (e.g., DISSIPATE in English and DISSIPARE in Italian). The 14 Doublet words were matched to 14 Control words that shared the same three initial letters but did not have a doublet (e.g., DISGRACE in English and DISGRAZIA in Italian; Appendix 1). In most cases the Control items included an intervocalic consonant cluster (e.g., SG). The reasons for this choice were twofold. First, it allowed matching Doublet and Control words in orthographic length 
(number of letters) and initial-syllable length (geminate consonants belong to the two syllables: Gili Fivela \& Zmarich, 2005; Loporcaro, 1996; Maddieson, 1984; Payne, 2005). Second, the consonant clusters in Control Italian words matched the consonant-vowel structure of the first syllable with Doublet words. This matching might be critical in Italian as vowel duration decreases when followed by a geminate (Chang, 2000; Esposito \& Di Benedetto, 1999), and more generally when included in closed syllables (relative to open syllables; e.g., Maddieson, 1984). ${ }^{1}$

\section{Procedure}

The experiment was conducted with Ductus (Guinet \& Kandel, 2010). At the beginning of each trial, the participants heard an auditory signal and saw a fixation point at the centre of a laptop screen. This fixation point was replaced by a word written in upper-case Times New Roman size 18. The participants had to write the word they saw as soon as it appeared on the computer screen. They were instructed to write it at a normal speed. They wrote the word with a special pen (Intuos Inking Pen) on a lined paper (vertical limit $=8 \mathrm{~mm}$, horizontal limit $=17 \mathrm{~cm}$ ) that was stuck to a digitizer (Wacom Intuos 2, sampling frequency $200 \mathrm{~Hz}$, accuracy $0.02 \mathrm{~mm}$ ). They had to write the words in upper-case letters and lift the pen between each letter in a small upward-downward movement. When the participant finished writing a word, the experimenter clicked on a button to present the following word. Prior to the experiment, the participants practiced lifting the pen between letters by writing their names several times until they thought they could do it "spontaneously" for the purposes of the experiment. We presented the 28 words in two blocks of 14 stimuli. The words were randomized across participants. There were 10 filler items so that there were more words that did not have double letters than words with double letters. There were two practice items before the beginning of the experimental session. The participants were tested individually in a quiet room. The whole session lasted $10-15 \mathrm{~min}$.

\section{Data processing and analysis}

To obtain the measures on latencies, letter and inter-letter interval durations, we used the data analysis module provided by Ductus. Latency concerned the time between the presentation of the word on the screen and the moment at which the participant started to write it (pressure $>0$ ). The movement data were smoothed with a Finite Impulse Response filter with a $12 \mathrm{~Hz}$ cut-off frequency (Rabiner \& Gold, 1975). The letter duration measure was the time the participants took to write a letter. To investigate whether the processing of a doublet spreads throughout the initial letters of the word, we had to compare the durations of letters that are made up of a different number of strokes (e.g., in DISSIPATE/DISGRACE, D has 3 strokes, I has $1, \mathrm{~S}$ has 3 , and $\mathrm{G}$ has 4 ). To control for this point, we normalized the

\footnotetext{
1 Our matching criteria caused Doublet words to be phonologically shorter than Controls in number of phonemes (see Appendix 2). The finding that similar criteria were associated to opposite observations in French and English (Kandel et al., 2013, 2014) suggests that the difference in number of phonemes is not critical to account for the data.
} 
duration values with respect to the number of strokes per letter. The letter segmentation was determined on the basis of a previous up-stroke/down-stroke analysis of each upper-case letter of the alphabet (Spinelli, Kandel, Guerassimovitch, \& Ferrand, 2012). We also measured the duration of the intervals between letters. For example, in DISSIPATE/DISGRACE, we measured the time that the pen was in the air at the intervals DI, IS and SS or SG, respectively. The interval duration was defined as the time period in which two letters were separated by a pen lift. The letter end corresponded to pressure $=0$ and the onset of the following letter corresponded to pressure $>0$.

We ran linear mixed-effect models (Pinheiro \& Bates, 2000; Snijder \& Bosker, 1999) using the software $\mathrm{R}$ ( $\mathrm{R}$ version 3.1.1, R Core Team, 2014) with the package lmerTest (Kuznetsova, Brockhoff, \& Christensen, 2014). The data for English was the same as in Kandel et al. (2013). The latter presented the data analysed with Analyses of Variance conducted on participants (F1) and items (F2). Below we present the same data but analysed with linear mixed effects models which take into account participant and item variability simultaneously. The statistical analyses on the English and Italian data were performed on interval durations for intervals I1 to I3 (e.g., Interval 1 (I1) = DI, Interval 2 (I2) = IS, Interval 3 (I3) = SS or SG), letter stroke durations from letters L1 to L4 (e.g., for DISSIPATE/DISGRACE and DISSIPARE/DISGRAZIA): Letter $1(\mathrm{~L} 1)=\mathrm{D}$, Letter $2(\mathrm{~L} 2)=\mathrm{I}$, Letter 3 $(\mathrm{L} 3)=\mathrm{S}$, Letter $4(\mathrm{~L} 4)=\mathrm{S}$ and $\mathrm{G})$ and latencies. Items and participants were included as random-effect variables. We conducted further analyses to compare the effect of letter doubling between the languages. We ran analyses on latencies with one fixed-effect variable: Word Type (Doublet versus Control). In a separate analysis, we compared the results to the ones presented in English by Kandel et al. (2013). For the analyses on stroke and interval durations, we included the two previous fixed-effect factors plus the position, L1-L4 and I1-I3 respectively. Finally, we computed a variable (Fourth Letter Identity) to take into account the fact that the fourth letter changed across Word Type Condition (e.g., for DISSIPATE/ DISGRACE and DISSIPARE/DISGRAZIA). This factor was included as randomeffect variable in the analyses on stroke and interval durations in order to control the variance part explained by this letter change.

The most complex adequate adjustment model (Bar, Levy, Scheepers, \& Tily, 2013)-i.e., the adjustment on intercept and slopes-was included on all the models. All the mixed-effects (the by-participants or by-items random slopes adjustments) were tested using likelihood ratio tests (Pinheiro \& Bates, 2000). The goodness-of-fit for each model (Pitt \& Myung, 2002) was evaluated using the Bayesian Information Criterion (BIC, Schwarz, 1978). The model with the most complex adjustment but with the smallest BIC was selected. For all the fixed-effects tests, $p$-values were obtained reporting $F$ values on the Fisher distribution (Type III ANOVA) with error degree of freedom calculation based on Satterthwaite's approximation (Kuznetsova et al., 2014) for latency, stroke and interval duration analyses. 


\section{Results}

\section{Inter-letter interval duration}

Figure 1 presents mean inter-letter durations for intervals 1-3 in English and Italian Doublet and Control words. We excluded 2.3\% of the data in English and $3.1 \%$ in Italian. The inclusion of participants, items and Fourth Letter Identity as randomeffect variables explained a significant part of the variance for each language $(p<.001)$.

\section{Italian}

There was one significant mixed-effect: The interaction between item and interval position (by-items random slopes adjustments for interval position, $\chi^{2}(5)=21.38$, $p<.001)$. Intervals for Doublet words were shorter than Controls, $\mathrm{F}(1$, $14.05)=5.36, p=.036$. Interval position yielded a significant effect, $\mathrm{F}(2$, $29.89)=7.68, p=.002$. The interaction between these two factors was significant, $\mathrm{F}(2,29.89)=4.58, p=.041$. Further analyses revealed that the intervals were significantly longer for Control than Doublet words at interval $2 \mathrm{t}(1215)=-2.02$, $p=.048)$ and interval $3 \mathrm{t}(41.28)=-3.3, p<.001)$.

\section{English}

None of the mixed-effects was significant. Type of Words did not yield a significant effect, $\mathrm{F}(1,14.98)=2.37, p=.144$. Interval position yielded a significant effect, $\mathrm{F}(2,1614.39)=7.49, p<.001$. The interaction between these two factors was significant, $\mathrm{F}(2,1614.37)=8.77, p<.001$. Further analyses revealed that the intervals were significantly longer for Control than Doublet words only at interval 3 $\mathrm{t}(22.00)=-2.12, p=.046)$.

\section{Letter stroke duration}

Figure 2 presents mean letter stroke durations for letters 1-4 in English and Italian Doublet and Control words. We excluded $0.4 \%$ of the data in English and $0.8 \%$ Italian. The inclusion of participants, items and Fourth Letter Identity as randomeffect variables explained a significant part of the variance for each language $(p<.001)$. None of the mixed-effects were significant for each language.

\section{Italian}

Stroke durations for Doublet words were shorter than controls, $F(1,17.25)=5.32$, $p=.034$. Letter position yielded also a significant effect, $\mathrm{F}(3,2133.05)=197.98$, $p<.001$. The interaction between the two factors was significant, $\mathrm{F}(3$, $2133.05)=31.55, p<.001$. The analyses further revealed that the stroke durations for Doublet words were numerically shorter than Controls at letters 1, 2, 3 and 4. 

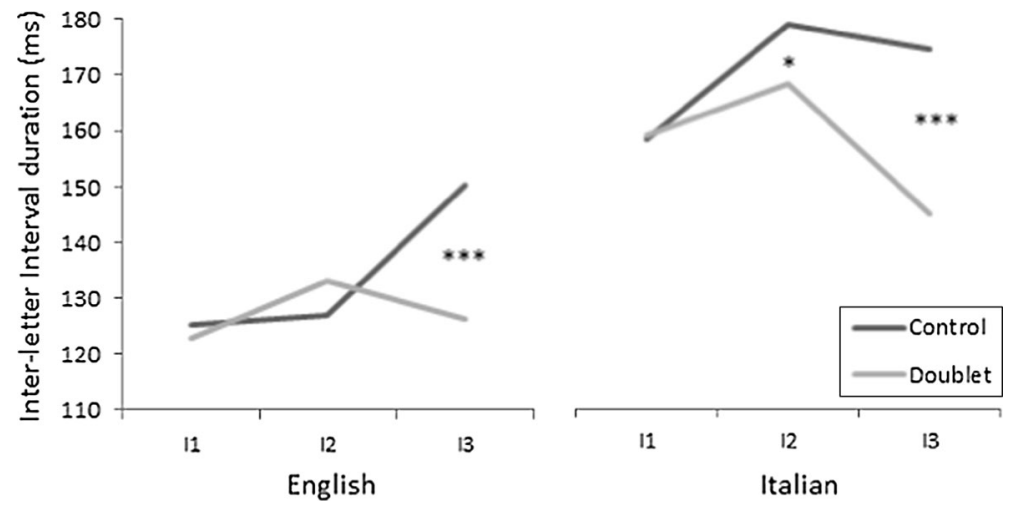

Fig. 1 Mean durations for intervals 1-3 in English and Italian words (e.g., DISSIPATE-DISSIPARE for Doublet words and DISGRACE-DISGRAZIA for Controls): Interval 1 (I1) = DI, Interval 2 (I2) = IS, Interval 3 (I3) $=$ SS/SG)
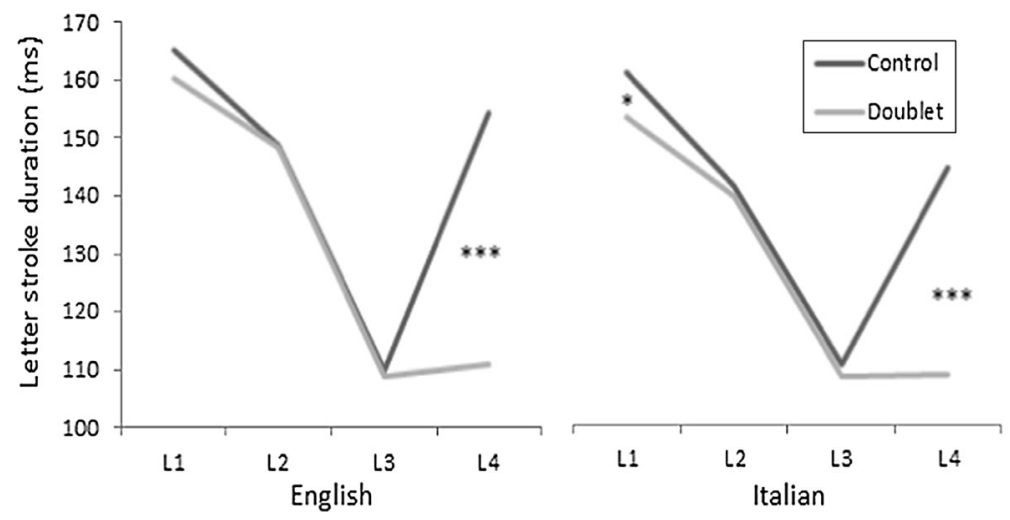

Fig. 2 Mean letter stroke durations for letters 1-4 in English and Italian words (e.g., DISSIPATEDISSIPARE for Doublet words and DISGRACE-DISGRAZIA for Controls): Letter 1 (L1) = D, Letter 2 $(\mathrm{L} 2)=\mathrm{I}$, Letter $3(\mathrm{~L} 3)=\mathrm{S}$, Letter $4(\mathrm{~L} 4)=\mathrm{S} / \mathrm{G})$

The difference was statistically significant for $\mathrm{L} 1 \mathrm{t}(26.00)=-2.47, p=.010$ and L4, $\mathrm{t}(17.71)=-7.49, \quad p<.001$. None of the others fixed-effects reached significance.

\section{English}

Word Type of did not yield a significant effect, $\mathrm{F}(1,19.5)=1.49, p=.236$. Letter position yielded a significant effect, $\mathrm{F}(3,2172.1)=232.74, p<.001$. The interaction between the two factors was significant, $F(3,2172.1)=47.55$, $p<.001$. The analyses further revealed that the stroke durations for Doublet words were numerically shorter than Controls at letters $1,2,3$ and 4 . The difference was significant only for $\mathrm{L} 4, \mathrm{t}(528.20)=-16.14, p<.001$. None of the other fixedeffects reached significance. 


\section{Latency}

Latencies higher than $3000 \mathrm{~ms}$ or below $300 \mathrm{~ms}$ were excluded ( $0.8 \%$ of the data). The remaining latencies that exceeded two standard deviations above or below the mean were also discarded (1.3 and 1.2\% of the data in English and Italian, respectively). Table 1 presents the mean latencies for Doublet and Control words in English and Italian.

The inclusion of participants and items as random-effect variables explained a significant part of the variance for each language $(p<.001)$. None of the mixedeffects reached significance $\left(\chi^{2}<1\right)$. Doublet words yielded shorter latencies than Control words for Italian $\mathrm{t}(513.30)=3.97, p<.001$. We observed the same pattern for English and the differences were very close to significance, $\mathrm{t}(518.70)=-1.92$, $p=.055$.

\section{Discussion}

This research investigated the impact of double letter coding on word writing. A previous experiment in English conducted by Kandel et al. (2013) indicated that letter doubling affected spelling retrieval as well as the processes involved in motor production. The present study examined whether letter doubling also affects word writing in Italian. Letter doublets have different kinds of phonological counterparts in English and Italian, so we examined whether the presence of doublets in a word would have different impacts on word writing. English and Italian adult native speakers wrote words on a digitizer. The words had a doublet embedded (e.g., DISSIPATE-DISSIPARE, respectively) and were matched to words without a doublet that shared the initial letters (e.g., DISGRACE-DISGRAZIA, respectively). We measured latencies as an indicator of the time required for spelling retrieval and movement preparation before starting to write. Then, once the movement started, we measured letter duration and the interval between the letters. The results globally revealed that the presence of doublets in a word affected the timing of writing. The participants took more time to produce Control words than Doublet words. However, the impact of doublets on word writing was stronger in Italian than English.

In Italian, the latencies for Doublet words were shorter than Controls. This indicates that letter doubling affected the processes involved in spelling retrieval

Table 1 Mean latencies in milliseconds (standard deviations in brackets) for Control and Doublet words in English and Italian

\begin{tabular}{llll}
\hline & Doublet & Control & All \\
\hline English & $1153(354)$ & $1198(407)$ & $1176(382)$ \\
Italian & $1484(517)$ & $1543(580)$ & $1514(549)$ \\
All & $1317(472)$ & $1370(529)$ & \\
\hline
\end{tabular}


and movement preparation before starting to write. The presence of doublets also affected the timing of motor processes. The data revealed that intervals 2 and 3 of Doublet words were shorter than Control words. The stroke durations for letters 1 and 4 followed the same pattern. This suggests that letter doubling affected word writing in Italian before and during movement production. In English, the latencies were also numerically shorter for Doublet words than Controls (the differences almost reached significance since $p=.055$ ). The inter-letter intervals were shorter for Doublet words than Controls at interval 3. Stroke durations for letter 4 in Doublet words were shorter than Control words. Therefore, in both languages, processing Doublet words was less time consuming than words that do not contain double letters. The Italian data confirm the English data presented by Kandel et al. (2013). The impact of letter doubling seems to be stronger in Italian than English because, although the data present similar numerical patterns, the statistical differences reached significance in more locations in Italian than English.

Letter doubling had more impact on latencies in Italian than English. This indicates that letter doubling in Italian modulated spelling retrieval and movement preparation processes before starting to write. The duration data revealed language differences on the regulation of movement production. In Italian the second interval (IS in the DISSIPARE-DISGRAZIA example)—i.e., the interval that preceded the doublet-was shorter in Doublet words than Controls. Furthermore, stroke durations for letter 1 also followed the same pattern in Italian. These differences did not reach significance in English. So gemination in Italian affected more the timing of the motor processes involved in word production than in English. This is in line with the idea that the phonological differences denoted by letter doublets in Italian and English affect the timing of motor production in different ways. In English, they seem to affect the late stages of the writing process, right before the doublet occurs within the word. The properties of the vowel that precedes the consonants inform about the presence or not of a doublet.

The results on letter stroke durations for both languages also indicated that double letter representation-i.e., central orthographic processing-had an impact on peripheral motor processing. Figure 2 shows that there were no major differences between the languages on letter stroke durations. We observed that stroke durations were shorter when writing letter 1 (e.g., letter D) in Doublet words (DISSIPATE/ DISSIPARE) than Control words (DISGRACE/DISGRAZIA). Letter D has the same shape and motor program for both kinds of words, so the timing differences could only result from the spelling processes that were still active when the participants started to write the words. This is evidence for an interaction between central and peripheral processes. One of the contributions of the present study is to extend this finding to Italian. This is noteworthy, since double letters in Italian have a different phonological counterpart that is not present in English. The results support the idea that (1) phonology affects writing production, as Qu et al. (2011) suggested for Chinese writing; and (2) that the central processes for spelling retrieval are not completely finished before movement initiation (e.g., Roux et al., 2013). This suggests that the Italian writing system also functions in an interactive manner. Since the presence of a doublet has an impact on the way the letters are written, it is likely that the orthographic representations Italians activate to write 
words containing doublets have a specific coding. These representations would code letter identity and order, but also letter quantity. Letter quantity will modulate the timing of movement production.

Another interesting pattern that appeared in both languages concerns the distribution of movement time throughout the initial part of the word. The stroke durations decreased progressively from letters 1-2 (from D to $\mathrm{I}$ in the example above) and 2-3 (I to S). Then they remained stable from letters 3-4 in Doublet words ( $S$ to $S$ ) but increased significantly from letters 3-4 in Controls ( $S$ to $G$ ). Following the rationale presented by Kandel et al. (2013, 2014) and Van Galen's (1991) model, there were no duration increases between letters 3-4 in Doublet words because the writing system processed letter 4 -i.e., the second letter of the doublet-before starting to write and during the production of the initial letters. In Controls, the increase indicates that letter 4 was not programmed beforehand. The effect of doublet processing during movement production was stronger in Italian, since interval 2 (IS) was shorter in Doublet words than Controls. These differences were even more important at interval 3 (SS in Doublet words and SG in Controls), indicating that letter 4 required much more processing in Control than Doublet words.

These experimental results are in line with the neuropsychological data on English and Italian dysgraphic patients. We observed that orthographic representations code the presence of a doublet in a word. Double letters seem to be chunked and function as an independent processing unit. This modulates the timing of motor production in such a way that the timing to produce a letter will depend on letter quantity rather than on letter identity. The results of the present study therefore have further implications than those of previous research on letter doubling, because they show that the effects associated to letter chunking and processing are also observed at the peripheral and late stages of writing. In addition, the on-line duration measures give us information on how this processing affects letter writing. In English and Italian the processing of the doublet facilitated spelling retrieval and motor production. A different pattern of data was found in French where the processing of the double letter chunk delays movement production (Kandel et al., 2014). The reason why letter doubling affects English/Italian and French word production in opposite ways is a matter of future research. It could be that in French, the processing of the doublet is done simultaneously to the processing of the following syllable. This could constitute a cognitive load that results in a duration increase, from latencies to movement production throughout the word. Since syllable structure is not a determinant factor for word processing in English (Cutler, Mehler, Norris, \& Segui, 1986), doublet and syllable processing mechanisms do not compete. The presence of a doublet can therefore be a cue to accelerate the processing before and while writing.

An alternative account of the differential effects of doublets across languages might be that the frequency of doublets differs across orthographies. Doublet encoding could be facilitated if encountered in print and produced frequently. For example, Kandel et al. (2011) found that bigram frequency modulated handwriting production in French adults. To address this question we analyzed the percentages of double letters in Italian, English and French using lexical corpora (PhonItalia for 
Italian, Goslin, Galluzi, \& Romani, 2014; Celex for English, Baayen, Piepenbrock, \& Gulikers, 1995; Lexique for French, New, Pallier, Ferrand, \& Mataos, 2001). The frequency analyses were restricted to bi- and tri-syllabic words. We expressed the frequency values in percentages because the numbers of lexical entries varied across corpora. Appendix 3 displays the results of the analysis. It revealed that the three languages include a large variety of consonant doublets though their distributional characteristics vary slightly across orthographies. For example, ZZ, CC and TT are more frequent in Italian than French and English. In contrast, NN and SS are more frequent in French. Overall the total percentages of words including doublets were similar (29.8, 21.6, and 24.8 for Italian, English, and French, respectively). In the second analysis, we examined the frequency of the doublets we used in the experiments. Again, the mean percentages of words sharing the doublets were roughly similar across languages (3.2, 3.1, and 4.2 for Italian, English, and French, respectively; all t tests with $p>.15$ ). In sum, the frequency of the letter doublets in the three languages does not seem to provide an adequate account of the empirical findings.

Finally, the on-line measures on letter and interval duration can cast light on the locus of the processing. The results indicated that doublet processing starts during movement preparation and ends at letter 3; i.e., when the doublet is actually written. So a further theoretical implication of this research is that the effects of letter doubling were observed on peripheral measures that appear late in the writing processes, as compared to the latency measures that are used in studies on lexical processing. This means that the activation of central spelling processes that were observed on latencies spread onto peripheral processing. This is evidence for a functional relationship between central and peripheral processes and shows the importance of studying word writing from an interactive perspective that takes into account the processes involved in spelling retrieval and motor production. The idea is not new and has been abundantly discussed in speech production (Kawamoto, Kello, Jones, \& Bame, 1998; Rastle, Harrington, Palethorpe, \& Coltheart, 2000). Several studies on written production in the last years integrated motor execution parameters with more central factors (Afonso et al., 2015a, 2015b; Álvarez et al., 2009; Delattre et al., 2006; Kandel et al., 2006, 2012; Lambert \& Quemart, 2015: Lambert et al., 2011; Sausset et al., 2012).

\section{Conclusion}

Our findings provide evidence that the presence of a doublet affects the timing of motor production before the letter is doubled. This observation reinforces the proposal that central processing spreads onto peripheral processing during movement execution (Roux et al., 2013). The data further indicates that the orthographic processing of the doublet was modulated by phonological information. Therefore, the timing of motor processes to produce a letter not only depends on its shape and the activation of the motor program, but also on the way the orthographic representations encode the letters for spelling retrieval. 
Acknowledgements We are extremely grateful to Alfonso Caramazza for his ideas and comments related to this research. We would also like to thank the Harvard University Cognitive Neuropsychology Laboratory for allowing Sonia Kandel conduct the English experiment of the cross-linguistic study presented in this manuscript. Thanks to Géraldine Grosjacques for her help in the Italian experiment. We acknowledge funding from the Agence Nationale de la Recherche ANR ECRIRE 14-C30-0013-01) attributed to Sonia Kandel and Cyril Perret). We thank the MSHS of Poitiers (USR-CNRS 3565) for technical support.

\section{Appendix 1}

Doublet and Control words in Italian and English

\begin{tabular}{|c|c|c|c|}
\hline \multicolumn{2}{|l|}{ Italian words } & \multicolumn{2}{|c|}{ English words ${ }^{\mathrm{a}}$} \\
\hline Doublet & Control & Doublet & Control \\
\hline BALLATA & BALCONE & BALLOT & BALCONY \\
\hline CARRUGIO & CARTIERA & CARRIER & CARING \\
\hline COLLARE & COLMARE & COLLAR & COLONY \\
\hline CORRIDOIO & CORPOREO & CORRIDOR & CORPORAL \\
\hline DISSIPARE & DISGRAZIA & DISSIPATE & DISGRACE \\
\hline DISSOLUTO & DISTINTO & DISSOLUTE & DISTINCT \\
\hline FERROSO & FERTILE & FERROUS & FERTILE \\
\hline MANNAIA & MANDATO & MANNER & MANAGE \\
\hline MARRONE & MARZIALE & MARROW & MARTIAL \\
\hline MASSONE & MASTINO & MASSIVE & MASTER \\
\hline PASSATA & PASTOSO & PASSIVE & PASTING \\
\hline PASSIVO & PASTORE & PASSION & PASTOR \\
\hline POLLAIO & POLMONE & POLLUTE & POLEMIC \\
\hline PRESSIONE & PRESTIGIO & PRESSURE & PRESTIGE \\
\hline
\end{tabular}

${ }^{a}$ From Kandel et al. (2013)

\section{Appendix 2}

Characteristics of the Italian and English words

\begin{tabular}{|c|c|c|c|c|}
\hline \multirow[t]{2}{*}{ Characteristics } & \multicolumn{2}{|c|}{ Italian words } & \multicolumn{2}{|c|}{ English words } \\
\hline & Doublet & Control & Doublet & Control \\
\hline Word frequency $(\mathrm{pm})^{\mathrm{a}}$ & 7.53 & 7.69 & 26.16 & 14.18 \\
\hline Number of letters & 7.57 & 7.57 & 7.14 & 6.93 \\
\hline Number of syllables & 3.21 & 3.07 & 2.21 & 2.29 \\
\hline Number of phonemes & 6.50 & 7.57 & 5.36 & 6.14 \\
\hline
\end{tabular}

\footnotetext{
${ }^{a}$ From CoLFIS (Bertinetto et al., 2008) for Italian and Celex (Baayen et al., 1995) for English
} 


\section{Appendix 3}

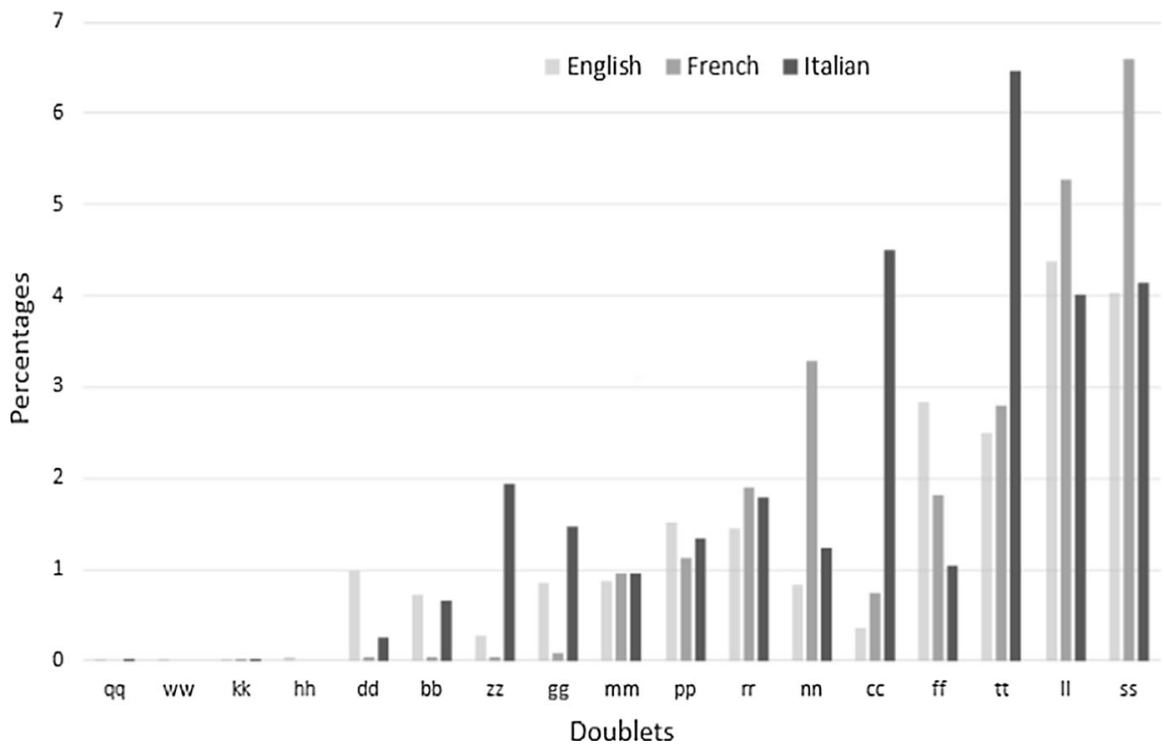

Percentages of words including double consonant letters in bi- and tri-syllabic words in Italian, English and French. Note Word corpora: PhonItalia for Italian, Goslin et al. (2014); Celex for English, Baayen et al. (1995); Lexique for French, New et al. (2001)

\section{References}

Afonso, O., \& Álvarez, C. J. (2011). Phonological effects in handwriting production: Evidence from the implicit priming paradigm. Journal of Experimental Psychology. Learning, Memory, and Cognition, 37(6), 1474-1483.

Afonso, O., Álvarez, C. J., \& Kandel, S. (2015b). Effects of grapheme-to-phoneme probability on writing durations. Memory \& Cognition, 43, 579-592.

Afonso, O., Suárez-Coalla, P., \& Cuetos, F. (2015a). Spelling impairments in Spanish dyslexic adults. Frontiers in Psychology, 6. doi:10.3389/fpsyg.2015.00466.

Álvarez, C. J., Cottrell, D., \& Afonso, O. (2009). Writing dictated words and picture names: Syllabic boundaries affect execution in Spanish. Applied Psycholinguistics, 30, 205-223.

Baayen, R. H., Davidson, D. J., \& Bates, D. M. (2008). Mixed-effects modeling with crossed random effects for subjects and items. Journal of Memory and Language, 59, 390-412.

Baayen, R. H., Piepenbrock, R., \& Gulikers, L. (1995). The CELEX lexical database [CD-ROM]. Philadelphia: Linguistic Data Consortium. University of Pennsylvania.

Bar, D. J., Levy, R., Scheepers, C., \& Tily, H. J. (2013). Random effects structure for confirmatory hypothesis testing: Keep it maximal. Journal of Memory and Language, 68, 255-278.

Berg, K. (2016). Double consonants in English: Graphemic, morphological, prosodic and etymological determinants. Reading and Writing, 29, 453-474.

Bertinetto, P. M., Burani, C., Laudanna, A., Marconi, L., Ratti, D., Rolando, C., et al. (2008). CoLFIS: Corpus e Lessico di Frequenza dell'Italiano Scritto Contemporaneo. http://www.ge.ilc.cnr.it/page. php?ID=archCoLFIS\&lingua $=\mathrm{it}$. 
Bonin, P., Peereman, R., \& Fayol, M. (2001). Do phonological codes constrain the selection of orthographic codes in written picture naming? Journal of Memory and Language, 45, 688-720.

Buchwald, A., \& Falconer, C. (2014). Cascading activation from lexical processing to letter-level processing in written word production. Cognitive Neuropsychology, 31, 606-621.

Caramazza, A., \& Miceli, G. (1990). The structure of graphemic representations. Cognition, 37, $243-297$.

Caramazza, A., Miceli, G., Villa, G., \& Romani, C. (1987). The role of the graphemic buffer in spelling: Evidence from a case of acquired dysgraphia. Cognition, 26, 59-85.

Carney, E. (1994). A survey of English spelling. London: Routledge.

Cassar, M., \& Treiman, R. (1997). The beginnings of orthographic knowledge: Children's knowledge of double letters in words. Journal of Educational Psychology, 89, 631-644.

Chang, W. (2000). Geminate vs. non-geminate consonants in Italian: Evidence from a phonetic analysis. University of Pennsylvania Working Papers in Linguistics: Vol. 7: Iss. 1, Article 6. http://repository. upenn.edu/pwpl/vol7/iss1/6.

Cutler, A., Mehler, J., Norris, D., \& Segui, J. (1986). The syllable's differing role in the segmentation of French and English. Journal of Memory and Language, 25(4), 385-400.

Delattre, M., Bonin, P., \& Barry, C. (2006). Written spelling to dictation: Sound-to-spelling regularity affects both writing latencies and durations. Journal of Experimental Psychology. Learning, Memory, and Cognition, 32(6), 1330-1340.

Ellis, A. W., Young, A., \& Flude, B. (1987). "Afferent dysgraphia” in a patient and in normal subjects. Cognitive Neuropsychology, 4, 465-486.

Esposito, A., \& Di Benedetto, M. G. (1999). Acoustical and perceptual study of gemination in Italian stops. Journal of the Acoustical Society of America, 106(4), 2051-2062.

Gili Fivela, B., \& Zmarich, C. (2005). Italian geminates under speech rate and focalization changes: kinematic, acoustic, and perception data. In Eurospeech, 9th European conference on speech communication and technology. Lisbon, Portugal, September 4-8, 2005.

Goslin, J., Galluzzi, C., \& Romani, C. (2014). PhonItalia: A phonological lexicon for Italian. Behavior Research Methods, 46, 872-886.

Guinet, E., \& Kandel, S. (2010). Ductus: A software package for the study of handwriting production. Behavior Research Methods, 42, 326-332.

Jenkins, J. J., \& Russel, W. A. (1952). Associative clustering during recall. Journal of Abnormal and Social Psychology, 47, 818-821.

Kandel, S., Álvarez, C., \& Vallée, N. (2006). Syllables as processing units in handwriting production. Journal of Experimental Psychology: Human Perception and Performance, 32(1), 18-31.

Kandel, S., Spinelli, E., Tremblay, A., Guerassimovitch, H. \& Álvarez, C. J. (2012). Processing prefixes and suffixes in handwriting production. Acta Psychologica, 140, 187-195.

Kandel, S., Peereman, R., \& Ghimenton, A. (2013). Further evidence for the interaction between central and peripheral processes: The impact of double in writing English words. Frontiers in Psychology (Research Topic "Writing words: From brain to hand(s)" - Section Cognitive Science), 4, 729.

Kandel, S., Peereman, R., \& Ghimenton, A. (2014). How do we code the letters of a word when we have to write it? Investigating double letter representation in French. Acta Psychologica, 148, 56-62.

Kandel, S., Peereman, R., Grosjacques, G., \& Fayol, M. (2011). For a psycholinguistic model of handwriting production: Testing the syllable-bigram controversy. Journal of Experimental Psychology: Human Perception and Performance, 37(4), 1310-1322.

Kandel, S., \& Spinelli, E. (2010). Processing complex graphemes in handwriting production. Memory \& Cognition, 38(6), 762-770.

Kandel, S., \& Valdois, S. (2006a). Syllables as functional units in a copying task. Language and Cognitive Processes, 21(4), 432-452.

Kandel, S., \& Valdois, S. (2006b). French and Spanish-speaking children use different visual and motor units during spelling acquisition. Language and Cognitive Processes, 21(5), 531-561.

Kawamoto, A. H., Kello, C. T., Jones, R., \& Bame, K. (1998). Initial phoneme versus whole-word criterion to initiate pronunciation: Evidence based on response latency and initial phoneme duration. Journal of Experimental Psychology. Learning, Memory, and Cognition, 24, 862-885.

Krämer, M. (2009). The phonology of Italian. New York: Oxford University Press Inc.

Kuznetsova, A., Brockhoff, P. B., \& Christensen, R. H. B. (2014). LmerTest: Tests for random and fixed effects for linear mixed effect models (lmer objects of lme4 packages. http://CRAN.R-project.org/ package=lmerTest/. 
Lambert, E., Alamargot, D., Larocque, D., \& Caporossi, G. (2011). Dynamics of the spelling process during a copy task: Effects of regularity and frequency. Canadian Journal of Experimental Psychology, 65(3), 141-150.

Lambert, E. \& Quemart, P. (2015). Ortho-syllables and syllables affect the dynamics of adjective handwriting in French. Céline Rémi; Lionel Prévost; Eric Anquetil. 17th Biennial Conference of the International Graphonomics Society, Pointe-à-Pitre, Guadeloupe. 2015, Drawing, Handwriting Processing Analysis: New Advances and Challenges.

Levelt, W. J. M. (1989). Speaking: From intention to articulation. Boston, MA: MIT Press.

Loporcaro, M. (1996). On the analysis of geminates in standard Italian and Italian dialects. In B. Hurch \& R. A. Rhodes (Eds.), Natural phonology. The state of the art (pp. 153-188). Berlin: Mouton de Gruyter.

Maddieson, I. (1984). Phonetic cues to syllabification. Working Papers in Phonetics, Department of Linguistics, UCLA, UC Los Angeles. http://escholarship.org/uc/item/2497n8jq.

Mattei, M., \& Di Benedetto, M. G. (2000). Acoustic analysis of singleton and geminate nasals in Italian. WEB-SLS: The European Student Journal of Language and Speech (online). http://acts.ing. uniroma1.it/Papers/J15-Mattei_al-EJLS00.pdf.

McCloskey, M., Badecker, W., Goodman-Schulman, R. A., \& Aliminosa, D. (1994). The structure of graphemic representations in spelling: Evidence from a case of acquired dysgraphia. Cognitive Neuropsychology, 11, 341-392.

Miceli, G., Benvengnú, B., Capasso, R., \& Caramazza, A. (1995). Selective deficit in processing double letters. Cortex, 31, 161-171.

New, B., Pallier, C., Ferrand, L., \& Matos, R. (2001). Une base de données lexicales du français contemporain: Lexique. L'Année Psychologique, 101, 447-462. http://www.lexique.org.

Pacton, S., Borchardt, G., Treiman, R., Lété, B., \& Fayol, M. (2014). Learning to spell from reading: General knowledge about spelling patterns influences memory for specific words. Quarterly Journal of Experimental Psychology, 67, 1019-1036.

Pacton, S., Perruchet, P., Fayol, M., \& Cleeremans, A. (2001). Implicit learning out of the lab: The case of orthographic regularities. Journal of Experimental Psychology: General, 130, 401-426.

Pacton, S., Sobaco, A., Fayol, M., \& Treiman, R. (2013). How does graphotactic knowledge influence children's learning of new spellings? Frontiers in Psychology (Research Topic "Writing words: From brain to hand(s)" - Section Cognitive Science), 4(701), 1-10.

Payne, E. M. (2005). Phonetic variation in Italian consonant germination. Journal of the International Phonetic Association, 35(2), 153-181.

Pinheiro, J. C., \& Bates, D. M. (2000). Mixed-effects models in S and S-PLUS. New York: Springer.

Pitt, M. A., \& Myung, I. J. (2002). When a good fit can be bad. Trends in Cognitive Sciences, 6, 421-425.

Qu, A., \& Damian, M. F. (2015). Cascadedness in Chinese written word production. Frontiers in Psychology, 6, 1271.

Qu, A., Damian, M. F., Zhang, Q., \& Zhu, X. (2011). Phonology contributes to writing: Evidence from written word production in a nonalphabetic script. Psychological Science, 22(9), 1107-1112.

$\mathrm{R}$ Core Team. (2014). R: A language and environment for statistical computing. $R$ Foundation for Statistical Computiong. Vienna, Austria. http://www.R-project.org/.

Rabiner, L. R., \& Gold, B. (1975). Theory and application of digital signal processing. Upper Saddle River, NJ: Prentice-Hall.

Rastle, K., Harrington, J., Palethorpe, S., \& Coltheart, M. (2000). Reading aloud begins when the computation of phonology is complete. Journal of Experimental Psychology: Human Perception and Performance, 26, 1178-1191.

Roux, J.-S., McKeeff, T. J., Grosjacques, G., Afonso, O., \& Kandel, S. (2013). The interaction between central and peripheral processes in handwriting production. Cognition, 127, 235-241.

Sausset, S., Lambert, E., Olive, T., \& Larocque, D. (2012). Processing of syllables during handwriting: Effects of graphomotor constraints. Quarterly Journal of Experimental Psychology, 65(10), $1872-1879$.

Schwarz, G. (1978). Estimating the dimension of a model. The Annals of Statistics, 6, 461-464.

Snijders, T. A. B., \& Bosker, R. J. (1999). Multilevel analysis: An introduction to basic and advanced multilevel modeling. London: Sage Publishers.

Spinelli, E., Kandel, S., Guerassimovitch, H., \& Ferrand, L. (2012). Graphemic cohesion effect in reading and writing complex graphemes. Language and Cognitive Processes, 27(5), 770-791.

Sternberg, S., Knoll, R. L., Monsell, S., \& Wright, C. E. (1983). Control of rapid action sequences in speech and typing. Murray Hill, NJ: AT\&T Bell Laboratories. 
Sternberg, S., Knoll, R. L., \& Turock, D. L. (1990). Hierarchical control in the execution of action sequences: Test of two invariance properties. In M. Jeannerod (Ed.), Attention and performance XIII: Motor representation and Control. Hillsdale, NJ: Erlbaum.

Tagliapietra, L., \& McQueen, J. M. (2010). What and where in speech recognition: Geminates and singletons in spoken Italian. Journal of Memory and Language, 63, 306-323.

Tainturier, M. J., \& Caramazza, A. (1996). The status of double letters in graphemic representations. Journal of Memory and Language, 36(1), 53-73.

Teulings, H. L., Thomassen, A. J. W. M., \& Van Galen, G. P. (1983). Preparation of partly precued handwriting movements: The size of movement units in handwriting. Acta Psychologica, 54, $165-177$.

Treiman, R., \& Kessler, B. (2015). Choosing between alternative spellings of sounds: The role of context. Journal of Experimental Psychology: Learning, Memory, and Cognition, 42(7), 1154.

Van Galen, G. P. (1991). Handwriting: Issues for a psychomotor theory. Human Movement Science, 10, 165-191.

Van Galen, G. P., Smyth, M. M., Meulenbroek, R. G. J., \& Hylkema, H. (1989). The role of short-term memory and the motor buffer in handwriting under visual and non-visual guidance. In R. Plamondon, C. Y. Suen, \& M. L. Simner (Eds.), Computer recognition and human production of handwriting (pp. 253-271). Singapore: World Scientific.

Venneri, A., Cubelli, R., \& Caffara, P. (1994). Perseverative dysgraphia: A selective disorder in writing double letters. Neuropsychologia, 32, 923-931.

Weingarten, R. (2005). Subsyllabic units in written word production. Writing Language Litterature, 8, 43-61.

Weingarten, R., Nottbusch, G., \& Will, U. (2004). Morphemes, syllables, and graphemes in written word production. In T. Pechmann \& C. Habel (Eds.), Multidisciplinary approaches to language production (pp. 529-572). Berlin: Mouton de Gruyter.

Wing, A. M., \& Baddeley, A. D. (1980). Spelling errors in handwriting: A corpus and a distributional analysis. In U. Frith (Ed.), Cognitive processes in spelling. London: Academic Press.

Zhang, Q., \& Damian, M. F. (2010). Impact of phonology on the generation of handwritten responses: Evidence from picture-word interference tasks. Memory \& Cognition, 38, 519-528. 